\title{
PENENTUAN HARGA KONTRAK OPSI TIPE ASIA MENGGUNAKAN MODEL SIMULASI NORMAL INVERSE GAUSSIAN (NIG)
}

\author{
I Putu Oka Paramartha ${ }^{1}$, Komang Dharmawan ${ }^{\S 2}$, Desak Putu Eka Nilakusmawati ${ }^{3}$ \\ ${ }^{1}$ Jurusan Matematika, Fakultas MIPA - Universitas Udayana [Email: putuparamartha@ gmail.com] \\ ${ }^{2}$ Jurusan Matematika, Fakultas MIPA - Universitas Udayana [Email: dharmawan.komang@gmail.com] \\ ${ }^{3}$ Jurusan Matematika, Fakultas MIPA - Universitas Udayana [Email: nilakusmawati_desak@yahoo.com] \\ ${ }^{\S}$ Corresponding Author
}

\begin{abstract}
The aim to determine of the simulation results and to calculate the stock price of Asian Option with Normal Inverse Gaussian (NIG) method and Monte Carlo method using MATLAB program. Results of both models are compared and selected a fair price. Besides to determine simulation accuracy of the stock price, speed of program execution MATLAB is calculated for both models for time efficiency. The first part, set variabels used to calculate the trajectory of stock prices at time $t$ to simulate the stock price at the time. The second part, simulate the stock price with NIG model. The third part, simulate the stock price with Monte Carlo model. After simulating the stock price, calculated the value of the pay-off of the Asian Option, and then estimate the price of Asian Option by averaging the entire value of pay-off from each iteration. The last part, compare result of both models. The results of this research is price of Asian Option calculated using Monte Carlo simulation and NIG. The rates were calculated using the NIG produce a fair price, because of the pricing contract NIG using four parameters $\alpha, \beta, \delta$, and $\mu$, while Monte Carlo is using only two parameters $\sigma$ and $\mu$. For execution time of the program, the Monte Carlo model is better in all iterations.
\end{abstract}

Keywords: Option, Asian Option, Normal Inverse Gaussian, NIG, Monte Carlo.

\section{PENDAHULUAN}

Opsi merupakan suatu kontrak atau perjanjian antara dua pihak, dengan pihak pertama adalah sebagai pembeli yang memiliki hak untuk membeli atau menjual dari pihak kedua yaitu penjual terhadap suatu aset tertentu pada harga dan waktu yang telah ditentukan (Tandelilin [1]). Sebagimana layaknya saham, opsi merupakan surat berharga yang dapat diperjualbelikan, namun yang diperjualbelikan adalah hak jual atau hak beli. Opsi tidak akan memiliki nilai apabila pada saat jatuh tempo pemegang opsi tidak menggunakan haknya.

Pasar opsi dibuka pertama kali pada bulan April 1973 yang berada di Chicago Board Options Exchange (CBOE). Namun, pada saat itu opsi yang diperdagangkan hanyalah opsi beli untuk saham. Di Indonesia, kontrak opsi pertama kali diperdagangkan pada oktober 2004 di Bursa Efek Jakarta. Aset induk yang dipilih dalam kontrak opsi di Indonesia saat itu adalah saham dari Telkom dengan jangka jatuh temponya 1 bulan. Hingga saat ini, opsi yang diperdagangkan tidak terbatas pada opsi saham saja, tetapi juga opsi indeks saham, opsi kurs valuta asing, opsi komoditas dan lain-lain.

Opsi bisa digunakan untuk meminimalkan risiko dan memaksimalkan keuntungan dengan daya ungkit (leverage) yang lebih besar. Berinvestasi dalam bentuk opsi juga memberikan fungsi lindung nilai (hedging) terhadap aset induk. Dengan dana 
investasi yang relatif kecil, persentase keuntungan yang diperoleh relatif lebih besar dibandingkan dengan investasi pada saham. Namun demikian, risiko yang ditanggung akan lebih besar. Dengan adanya opsi, investor memiliki pilihan untuk menempatkan dananya dalam berbagai jenis instrument yang bertujuan mengurangi tingkat risiko.

Hal yang menarik tentang opsi di pasar modal adalah dalam penetapan nilai kontrak opsi. Harga opsi saham adalah refleksi dari nilai intrinsik opsi. Nilai intrinsik opsi adalah nilai ekonomis opsi jika opsi tersebut ditebus, yaitu sebesar selisih antara harga saham saat pelaksanaan opsi dengan harga opsi saham yang telah dibayarkan. Penetapan harga opsi saham bertujuan untuk menentukan harga yang seimbang antara pembeli opsi dan penjual opsi sehingga tidak ada pihak yang terlalu diuntungkan atau dirugikan. Dengan semakin berkembangnya opsi, maka semakin berkembang pula cara-cara dalam memprediksi suatu pergerakan harga opsi dan meramalkan segala kemungkinan yang terjadi yang bertujuan untuk meminimalkan risiko dan memaksimalkan keuntungan.

Untuk menentukan harga kontrak opsi dapat digunakan berbagai model simulasi, salah satu diantaranya adalah simulasi Monte Carlo. Simulasi Monte Carlo atau Monte Carlo Simulation (MCS) seringkali digunakan untuk menentukan nilai opsi, berdasarkan sekumpulan data historis. Simulasi ini dikelompokkan sebagai metode sampling, karena inputnya dihasilkan secara acak dari distribusi probabilitas, untuk mensimulasikan proses sampling dari populasi sebenarnya (Korn, et al. [2]). Seiring dengan semakin kompleksnya saham yang ada, maka banyak sekali lompatan dan Volatility Clustering yang terjadi pada saham. Volatility Clustering terjadi ketika harga saham menunjukkan adanya perubahan yang sangat tinggi pada fase tertentu, kemudian diikuti oleh perubahan yang tidak begitu tinggi pada fase berikutnya. Penelitian ini menggunakan model Normal Inverse Gaussian (NIG) untuk menentukan harga kontrak opsi, karena model NIG memiliki keunggulan yakni mampu menangkap perilaku logreturn dari suatu harga saham dan juga dianggap mampu dengan baik menangani Volatility Clustering yang terjadi (Dharmawan [3]).

Hasil harga opsi yang didapatkan dengan menggunakan model NIG akan dibandingkan dengan hasil harga opsi yang didapatkan dengan model Monte Carlo dan akan dicari mana yang lebih murah/adil(fair). Hasil yang didapat akan digunakan sebagai acuan pembuatan kontrak yang ideal. Data yang digunakan dalam penelitian ini adalah data saham PT. Telkom, karena selain telah go public sejak 14 November 1995, PT. Telkom juga merupakan salah satu perusahaan go public sektor telekomunikasi yang memiliki nilai kompetitif dalam bersaing dengan perusahaan-perusahaan lainnya.

\section{METODE PENELITIAN}

Jenis penelitian yang dilakukan adalah studi kasus terhadap harga Opsi Tipe Asia yang sahamnya berasal dari PT. Telkom. Studi kasus yang dilakukan adalah dengan mensimulasikan data saham yang didapat guna menaksir harga opsi yang sesuai. Data yang digunakan dalam penelitian ini adalah data sekunder, yang bersumber dari internet.

Langkah-langkah untuk mencari harga opsi Tipe Asia dengan menggunakan metode NIG:

1) Menentukan $S_{0}$ (harga saham awal), $K$ (harga pelaksanaan), $T$ (waktu jatuh tempo),dan $r$ (suku bunga bebas risiko), 2) Menentukan return dari data saham PT. Telkom dengan persamaan:

$$
R_{t}=\ln \left(\frac{S_{t+1}}{S_{t}}\right)
$$

3) Menentukan statistik deskriftif yang terdiri dari mean $(\mathrm{E})$, variance $(\mathrm{V})$, skewness $(\mathrm{S})$, dan kurtosis (K) dari data return PT. Telkom, 4) Menetapkan nilai taksiran parameter yang terdiri dari $\alpha, \beta, \delta$, dan $\mu$. Parameter $\alpha$ menyatakan kurtosis, $\beta$ menyatakan skewness, $\mu$ menyatakan lokasi dan $\delta$ menyatakan skala dari fungsi densitas NIG. Parameter NIG dapat dihitung dengan persamaan: 


$$
\begin{aligned}
& \alpha=\sqrt{\frac{3 K-4 S^{2}-9}{V\left(K-\frac{5}{3} S^{2}-3\right)^{2}}} \\
& \beta=\frac{S}{\sqrt{V\left(K-\frac{5}{3} S^{2}-3\right)}} \\
& \delta=3^{\frac{3}{2}} \frac{\sqrt{V\left(K-\frac{5}{3} S^{2}-3\right)}}{3 K-4 S^{2}-9} \\
& \mu=E-\frac{3 S \sqrt{V}}{3 K-4 S^{2}-9}
\end{aligned}
$$

Persamaan di atas hanya berlaku untuk $\left(3 K-4 S^{2}\right)>0$. Jika syarat itu tidak terpenuhi maka digunakan nilai $\alpha=1, \beta=0$ dan $\delta=0.01$,

5) Melakukan simulasi harga saham dengan simulasi NIG. Untuk mensimulasi harga saham yang harus dilakukan pertama adalah menentukan bilangan acak NIG dengan persamaan:

$$
X_{t}^{N I G}=\mu+\beta \delta^{2} I_{t}+\delta W I_{t}
$$

Dengan $W=\left\{W_{t}, t \geq 0\right\}$ adalah gerak Brown dan proses IG $I=\left\{I_{t}, t \geq 0\right\}$ dengan parameter $a=1$ dan $b=\delta \sqrt{\alpha^{2}-\beta^{2}}, \alpha>0, \delta>0, \alpha>|\beta|, \mu \in R$.

Setelah mendapatkan bilangan acak NIG, maka harga saham dapat disimulasikan dengan persamaan:

$$
S_{t}=S_{0} \cdot \exp \left(m t+\bar{X}_{t}^{N I G}+\omega t\right)
$$

Dengan

$$
\omega=\delta\left(\sqrt{\alpha^{2}-(\beta+1)^{2}}-\sqrt{\alpha^{2}-\beta^{2}}\right)
$$

Dan $m$ adalah selisih dari suku bunga dengan deviden.

6) Merata-ratakan seluruh hasil harga saham simulasi dengan persamaan:

$$
\bar{S}_{T}=\sum_{i=1}^{N} \frac{S\left(t_{i}\right)}{N}
$$

7) Menghitung harga kontrak Opsi Tipe Asia menggunakan nilai dari rata-rata harga saham yang telah didapat sebelumnya dengan persamaan:

$$
C=e^{-r T} \max \left(\bar{S}_{T}-K, 0\right)
$$

8) Merata-ratakan seluruh hasil harga kontrak Opsi Tipe Asia, 9) Membandingkan hasil kontrak Opsi Tipe Asia dengan model NIG dengan model Monte Carlo, 10)
Menginterpretasi hasil perbandingan kedua model.

\section{HASIL DAN PEMBAHASAN}

A. Data Penelitian

Data Penelitian yang digunakan pada penilitian ini adalah data historis penutupan harian saham PT. Telkom periode 1 Maret 2012 sampai 1 Maret 2014.

B. Variabel-Variabel untuk Penentuan

Harga Saham dan Opsi Tipe Asia

Variabel yang digunakan untuk menentukan harga saham dan Opsi Tipe Asia meliputi $S_{0}$ (harga saham awal), $T$ (waktu jatuh tempo), $K$ (harga pelaksanaan), $r$ (suku bunga bebas risiko yang dikeluarkan oleh pihak yang berwenang). Nilai $S_{0}$ dapat dilihat pada data historis penutupan harga saham PT. Telkom terbaru yaitu sebesar 2325. Waktu jatuh tempo opsi ditentukan selama enam bulan, sedangkan untuk suku bunga bebas risikonya sebesar 7.5\% yang dikeluarkan oleh Bank Indonesia. Harga pelaksanaan disepakati antara penjual dan pembeli opsi yang ditentukan sebesar 2340 .

\section{Menentukan Nilai Return (Tingkat}

Pengembalian) Saham

Menentukan nilai Rt (Return saham pada waktu $t$ ) dengan persamaan (1). Data historis penutupan harga saham PT. Telkom akan disubstitusi ke persamaan (1) untuk menghitung Rt. Penghitungan yang akan dilakukan adalah menghitung nilai $R t$ saat $t=1$ sebagai berikut:

$$
\begin{aligned}
R_{1} & =\ln \left(\frac{1430}{1400}\right) \\
& =0.0212
\end{aligned}
$$

D. Menentukan Nilai Mean, Variance,

Skewness, dan Kurtosis

Nilai statistik deskriptif yang akan dicari dalam proses ini didapat dengan memanfaatkan data nilai Return $\left(R_{t}\right)$ PT. Telkom. Langkah yang akan dilakukan adalah menghitung nilai mean (E), variance (V), skewness (S), dan kurtosis (S) dari nilai Return $\left(R_{t}\right)$ saham PT. Telkom menggunakan software MATLAB, 
sehingga didapat hasil pada Tabel 1.

Tabel 1 Nilai statistik deskriptif untuk model NIG

\begin{tabular}{|c|c|}
\hline & Nilai \\
\hline Mean (E) & 0.00104 \\
\hline Variance (V) & 0.02131 \\
\hline Skewness (S) & -0.07164 \\
\hline Kurtosis (K) & 3.766102 \\
\hline
\end{tabular}

Dari Tabel 1 dapat dilihat bahwa model NIG memiliki bentuk yang tidak simetris, yaitu mencong ke kiri karena memiliki nilai skewness negatif, dan memiliki ekor gemuk (fat tail) dilihat dari nilai kurtosis yang cukup besar yaitu 3,766102, normalnya 3 yang disebabkan banyaknya data extrem pada data yang diakibatkan oleh Volatility Clustering.

E. Menentukan Nilai Parameter Awal $\alpha, \beta, \delta$, dan $\mu$

Parameter-parameter awal dari proses NIG akan ditentukan menggunakan metode moment. Dengan menggunakan nilai statistik deskriptif yang telah didapat pada Tabel 1, maka akan dapat dihitung nilai-nilai dari parameter awal NIG. Langkah pertama adalah menghitung nilai $\alpha$ yang menunjukkan kurtosis dari fungsi densitas NIG menggunakan persamaan 2

$$
\begin{aligned}
\alpha & =\sqrt{\frac{3 K-4 S^{2}-9}{V\left(K-\frac{5}{4} S^{2}\right)^{2}}} \\
& =\sqrt{\frac{3(3.766102)-4(-0.07164)^{2}-9}{0.02131\left((3.766102)-\frac{5}{4}(-0.07164)^{2}\right)^{2}}} \\
& =13.6475
\end{aligned}
$$

Langkah kedua adalah menghitung nilai $\beta$ yang menunjukkan skewness dari fungsi densitas NIG menggunakan persamaan 3

$$
\begin{aligned}
& \beta=\frac{S}{\sqrt{V}\left(K-\frac{5}{3} S^{2}-3\right)} \\
& =\frac{-0.07164}{\sqrt{0.02131}\left(3.766102-\frac{5}{3}(-0.07164)^{2}-3\right)} \\
& =-0.6479
\end{aligned}
$$

Langkah ketiga adalah menghitung nilai $\delta$ yang menunjukkan skala dari fungsi densitas NIG menggunakan persamaan 3

$$
\begin{aligned}
& \delta=3 \frac{3}{2} \frac{\sqrt{V\left(K-\frac{5}{3} S^{2}-3\right.}}{3 K-4 S^{2}-9} \\
& =3 \frac{3}{2} \frac{\sqrt{0.02131\left(3.766102-\frac{5}{3}(-0.07164)^{2}-3\right.}}{3(3.766102)-4(-0.07164)^{2}-9} \\
& =0.2898
\end{aligned}
$$

Langkah keempat adalah menghitung nilai $\mu$ yang merupakan lokasi puncak dari fungsi densitas NIG menggunakan persamaan 4

$$
\begin{aligned}
& \mu=E-\frac{3 S \sqrt{V}}{3 K-4 S^{2}-9} \\
& =0.00104-\frac{3(-0.07164) \sqrt{0.02131}}{3(3.766102)-4(-0.07164)^{2}-9} \\
& =0.0148
\end{aligned}
$$

Nilai-nilai dari $\alpha, \beta, \delta$, dan $\mu$ disajikan dalam Tabel 2.

Tabel 2 Nilai Parameter Awal Menggunakan Metode Moment

\begin{tabular}{|c|c|}
\hline & Nilai \\
\hline$\alpha$ & 13.6475 \\
\hline$\beta$ & -0.6479 \\
\hline$\delta$ & 0.2898 \\
\hline$\mu$ & 0.0148 \\
\hline
\end{tabular}

Nilai parameter NIG pada Tabel 2 tersebut akan digunakan untuk mensimulasikan harga saham $\left(S_{t}\right)$.

\section{F. Simulasi Harga Saham NIG}

Simulasi harga saham dengan NIG akan menggunakan algoritma NIG serta mengikutsertakan pembangkitan bilangan acak. Algoritma NIG memerlukan pengulangan dan perhitungan yang amat kompleks, sehingga umumnya dilakukan dengan menggunakan komputer. Simulasi ini diproses melalui banyak iterasi dengan variabel acak yang berbeda dan untuk memperkirakan harga saham yang akan datang. Dimana dilakukan beberapa simulasi kemudian harga saham dapat diperoleh dengan merata-ratakan simulasi yang terjadi.

Untuk melakukan simulasi harga saham, langkah awal yang harus dilakukan adalah membangkitkan bilangan acak NIG dengan persamaan (6) menggunakan nilai-nilai dari 
parameter NIG yaitu $\alpha, \beta, \delta$, dan $\mu$ pada Tabel 2. Setelah membangkitkan bilangan acak NIG, langkah selanjutnya adalah mensimulasi harga saham dengan persamaan (7) dengan $S_{0}$ sebesar 2325 dan dalam jangka waktu 6 bulan. Agar pengamatan lebih mudah dilakukan, maka simulasi yang akan ditampilkan hanya sebatas 100 kali simulasi, yang disajikan pada Gambar 1. Akan tetapi pada penelitian ini hasil yang dipergunakan adalah hasil dari simulasi yang dijalankan sebanyak 1.000.000 simulasi. Proses simulasi harga saham ini dihitung dengan bantuan software MATLAB R2013a, hasil yang didapat adalah sebagai berikut:

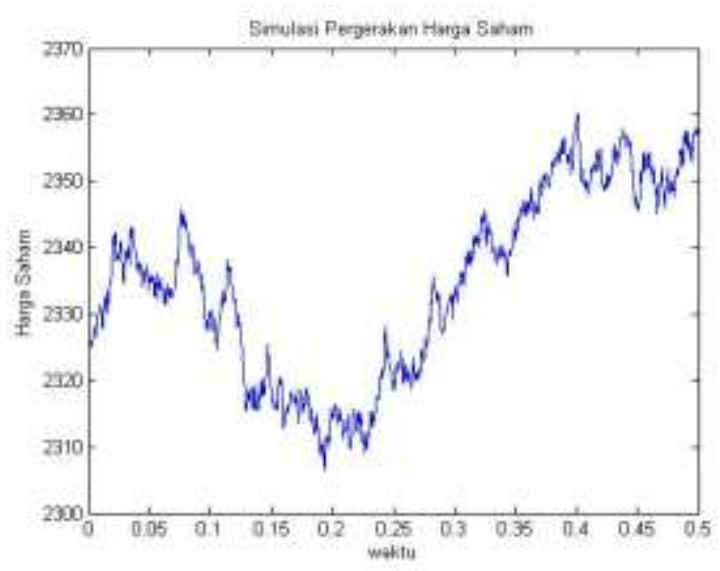

Gambar 1. Grafik Pergerakan Harga Saham $\left(S_{t}\right)$ dengan 100 Simulasi Selama 6 Bulan

Pada Gambar 1 dapat dilihat bahwa simulasi yang dilakukan 100 kali simulasi akan menghasilkan pergerakan harga saham yang memiliki tren harga naik. Setelah mendapatkan harga saham $\left(S_{t}\right)$, maka hasil dari simulasi harga saham $\left(\mathrm{S}_{\mathrm{t}}\right)$ pada Gambar 1 akan dicari nilai rata-ratanya $\left(\bar{S}_{t}\right)$ dengan persamaan (8) sehingga akan menghasilkan sebanyak 100 rata-rata harga saham $\left(\bar{S}_{t}\right)$.

\section{G. Penentuan Harga Kontrak Opsi Tipe Asia Menggunakan Simulasi NIG}

Harga kontrak Opsi Tipe Asia akan dicari menggunakan rata-rata harga saham $\left(\bar{S}_{t}\right)$ yang telah didapatkan melalui simulasi NIG. Nilai $\bar{S}_{t}$ yang telah didapat akan dimasukkan pada persamaan (9) dengan nilai $r$, $T$, dan $K$ yang sudah ditentukan, sehingga akan didapat 1.000.000 kali harga kontrak Opsi Tipe Asia.
Rata-rata dari seluruh harga kontrak Opsi Tipe Asia merupakan harga akhir kontrak opsi yang dicari. Pada Tabel 3 akan diperlihatkan untuk harga kontrak Opsi Tipe Asia dan waktu eksekusi programnya yang dihitung menggunakan simulasi NIG yang dilakukan dengan beberapa kali simulasi yang dijalankan pada program MATLAB R2013a dan harga kontrak Opsi Tipe Asia yang akan digunakan dalam penelitian ini adalah harga kontrak dengan simulasi sebanyak 1.000.000 simulasi, karena semakin banyak simulasi yang akan dilakukan maka nilai yang didapat akan menuju konvergen ke harga aslinya.

Tabel 3. Harga Kontrak Opsi Tipe Asia Menggunakan Simulasi NIG

\begin{tabular}{|c|c|c|}
\hline $\begin{array}{c}\text { Jumlah } \\
\text { Simulasi }\end{array}$ & Harga Opsi & $\begin{array}{c}\text { Waktu } \\
\text { Eksekusi }\end{array}$ \\
\hline 100 & 65.95 & 0.161 detik \\
\hline 1000 & 65.84 & 0.344 detik \\
\hline 10000 & 65.74 & 1.815 detik \\
\hline 100000 & 65.67 & 16.649 detik \\
\hline 1000000 & 65.63 & 180.305 detik \\
\hline
\end{tabular}

H. Penentuan Harga Kontrak Opsi Tipe Asia Menggunakan Simulasi Monte Carlo

Untuk menentukan harga kontrak Opsi Tipe Asia dengan simulasi Monte Carlo hal pertama yang dilakukan adalah melakukan simulasi harga saham dengan persamaan:

$$
S_{t}=S_{0} \cdot e^{\left(\left(r-\frac{\sigma^{2}}{2}\right) T+\sigma \epsilon \sqrt{T}\right)}
$$

Kemudian harga kontrak Opsi Tipe Asia dengan simulasi Monte Carlo akan dihitung menggunakan rata-rata harga saham $\left(\bar{S}_{t}\right)$ dengan persamaan (8) yang telah didapatkan melalui simulasi $S_{t}$ dengan persamaan (10). Nilai $\bar{S}_{t}$ yang telah dapat akan dimasukkan pada persamaan (9) dengan nilai $\mu$ sebesar $0.075, r$ sebesar $0.075, T$ selama 6 bulan, $K$ sebesar 2340, $\mathrm{S}_{0}$ sebesar 2325 dan $\sigma$ sebesar 0.0213 yang dihitung dengan bantuan software MATLAB R2013a, sehingga akan didapat 1.000.000 kali harga kontrak Opsi Tipe Asia. Rata-rata dari seluruh harga kontrak Opsi Tipe Asia merupakan harga akhir kontrak opsi yang 
dicari. Pada Tabel 4 akan diperlihatkan untuk harga kontrak Opsi Tipe Asia dan waktu eksekusi programnya yang dihitung menggunakan simulasi Monte Carlo yang dilakukan dengan beberapa kali simulasi yang dijalankan pada program MATLAB R2013a dan harga kontrak Opsi Tipe Asia yang akan digunakan dalam penelitian ini adalah harga kontrak dengan simulasi sebanyak 1.000 .000 simulasi, karena semakin banyak simulasi yang akan dilakukan maka nilai yang didapat akan menuju konvergen ke harga aslinya.

Tabel 4. Harga Kontrak Opsi Tipe Asia Menggunakan Simulasi Monte Carlo

\begin{tabular}{|c|c|c|}
\hline $\begin{array}{c}\text { Jumlah } \\
\text { Simulasi }\end{array}$ & Harga Opsi & $\begin{array}{c}\text { Waktu } \\
\text { Eksekusi }\end{array}$ \\
\hline 100 & 70.96 & 0.128 detik \\
\hline 1000 & 70.85 & 0.172 detik \\
\hline 10000 & 70.79 & 0.340 detik \\
\hline 100000 & 70.77 & 2.166 detik \\
\hline 1000000 & 70.75 & 22.873 detik \\
\hline
\end{tabular}

I. Interpretasi Perbandingan Harga Kontrak Opsi Tipe Asia Menggunakan Simulasi NIG dengan Monte Carlo

Perbandingan harga kontrak Opsi Tipe Asia menggunakan simulasi NIG dengan Monte Carlo dapat dilihat pada Tabel 5

Tabel 5. Perbandingan Harga kontrak Opsi Tipe Asia Menggunakan simulasi NIG dengan Monte Carlo

\begin{tabular}{|c|c|c|c|c|}
\hline \multirow{2}{*}{$\begin{array}{c}\text { Jumlah } \\
\text { Simulasi }\end{array}$} & \multicolumn{2}{|c|}{ NIG } & \multicolumn{2}{c|}{ Monte Carlo } \\
\cline { 2 - 5 } & Harga & Waktu & Harga & Waktu \\
\hline 100 & 65.95 & $\begin{array}{c}0.161 \\
\text { detik }\end{array}$ & 70.96 & $\begin{array}{c}0.128 \\
\text { detik }\end{array}$ \\
\hline 1000 & 65.84 & $\begin{array}{c}0.344 \\
\text { detik }\end{array}$ & 70.85 & $\begin{array}{c}0.172 \\
\text { detik }\end{array}$ \\
\hline 10000 & 65.74 & $\begin{array}{c}1.815 \\
\text { detik }\end{array}$ & 70.79 & $\begin{array}{c}0.340 \\
\text { detik }\end{array}$ \\
\hline 100000 & 65.67 & $\begin{array}{c}16.649 \\
\text { detik }\end{array}$ & 70.77 & $\begin{array}{c}2.166 \\
\text { detik }\end{array}$ \\
\hline 1000000 & 65.63 & $\begin{array}{c}180.305 \\
\text { detik }\end{array}$ & 70.75 & $\begin{array}{c}22.873 \\
\text { detik }\end{array}$ \\
\hline
\end{tabular}

Hasil interpretasi dari harga kontrak Opsi Tipe Asia yang sudah didapatkan dengan menggunakan model simulasi NIG dan model simulasi Monte Carlo adalah sebagai berikut:
1) Harga kontrak Opsi Asia yang diperoleh dengan menggunakan model simulasi NIG saat nilai $S_{0}=2325, r=0.075, T=0.5, K=$ $2340, \quad \alpha=13.6475, \quad \beta=-0.6479, \quad$ dan $\delta=0.2898$ adalah sebesar 65.63 dengan waktu eksekusi program selama 180.305 detik. Sedangkan harga kontrak Opsi Tipe Asia yang diperoleh dengan menggunakan model simulasi Monte Carlo saat nilai nilai $S_{0}=2325$, $r=0.075, T=0.5, K=2340, \mu=0.075$ dan $\sigma=0.0213$ adalah sebesar 70.75 dengan waktu eksekusi program selama 22.873 detik.

2) Berdasarkan hasil pada Tabel 5 dapat dilihat bahwa harga kontrak Opsi Tipe Asia yang dihitung dengan model NIG akan memberikan harga yang lebih fair dibandingkan dengan model Monte Carlo ini dilihat dari banyaknya parameter yang dilibatkan dalam penentuan harga kontrak Opsi Tipe Asia yang dihasilkan. Dalam penentuan harga kontrak Opsi Tipe Asia menggunakan model NIG parameter-parameter yang dilibatkan lebih banyak yaitu kurtosis $(\alpha)$, skewness $(\beta)$, skala $(\delta)$ dan lokasi puncak $(\mu)$ dari fungsi densitas NIG. Sedangkan pada metode Monte Carlo, dalam menentukan harga kontrak Opsi Tipe Asia hanya melibatkan dua parameter yaitu volatilitas $(\sigma)$ dan rata-rata return $(\mu)$.

\section{SIMPULAN}

Hasil simulasi Normal Inverse Gaussian (NIG) memberikan harga kontrak Opsi Tipe Asia PT.Telkom sebesar 65.63 Rupiah, sedangkan Monte Carlo memberikan harga kontrak Opsi Tipe Asia sebesar 70.75 Rupiah. Berdasarkan kedua hasil tersebut dapat disimpulkan bahwa harga kontrak Opsi Tipe Asia yang dihitung dengan model NIG akan memberikan harga yang lebih fair dibandingkan dengan model Monte Carlo, ini dilihat dari banyaknya parameter yang dilibatkan dalam penentuan harga kontrak Opsi Tipe Asia yang dihasilkan. Dalam penentuan harga kontrak Opsi Tipe Asia menggunakan model NIG parameter-parameter yang dilibatkan lebih banyak yaitu kurtosis $(\alpha)$, skewness $(\beta)$, skala $(\delta)$ dan lokasi puncak $(\mu)$ 
dari fungsi densitas NIG. Sedangkan pada metode Monte Carlo, dalam menentukan harga kontrak Opsi Tipe Asia hanya melibatkan dua parameter yaitu volatilitas $(\sigma)$ dan rata-rata return $(\mu)$. Akan tetapi, dari seluruh simulasi yang digunakan dalam penelitian ini model NIG kalah cepat dibandingkan dengan model Monte Carlo dalam hal pengeksekusian program Matlab

\section{DAFTAR PUSTAKA}

[1] Tandelilin, Eduardus. 2001. Analisis Investasi dan Manajemen Portofolio. Edisi Pertama. BPFE. Yogyakarta.

[2] Korn, R., E. Korn, and G. Kroisandt. 2010. Monte Carlo Methods and Models in Finance and Insurance. UK: Taylor and Francis Group, LLC.

[3] Dharmawan, Komang. 2013. Estimasi Nilai VaR Menggunakan Simulasi Proses Levy. Prosiding. Seminar Nasional Matematika dan Pendidikan Matematika FMIPA UNY Yogyakarta. 